\title{
A Study on Cost-effective Treatment of Wastewater and Odor Reduction for Southeast Asian Market Entry
}

\author{
Min-Jae Jung*, Yong-Do Kim**, Lee-Seung Kwon***, Woo-Sic Lee****, Woo-Taeg Kwon ${ }^{* * * * *}$ \\ Received: October 31, 2018. Revised: November 30, 2018. Accepted: December 05, 2018.
}

\section{Abstract}

Purpose - The purpose of this study is to apply a cost effective ultrasonic odor reduction method that generated micro-bubbles using ejector to the Southeast Asian wastewater market.

Research design, data, and methodology - A leather maker located in Ansan-city, Gyunggi-do, South Korea was sampled from the collection tank to select experimental materials. Experimental setup consisted of circulating water tank-air ejector-ultrasonic device, and circulating wastewater. Sample analysis was performed by CODcr, T-N, T-P, and turbidity by the National Environmental Science Institute.

Results - Experimental results show that it is most effective in removing odors when the frequency range of ultrasonic wave is $60 \sim 80 \mathrm{Khz}$ and the output is $200 \mathrm{~W}$. It showed that the concentration of complex odor dropped from a maximum of 14,422 times to a minimum of 120 times. Also, analysis of ammonia and hydrogen sulfide in specific odor substances has shown that they were reduced from $1.5 \mathrm{ppm}$ to $0.4 \mathrm{ppm}$ and from $0.6 \mathrm{ppm}$ to $0.1 \mathrm{ppm}$, respectively.

Conclusions - It is possible to shorten more than 12 hours in the treatment of micro-organisms. It can be seen that the processing time of odor after ultrasonic treatment in the pre-treatment facility is reduced by $25 \%$ when compared to the resultant micro-organisms after the chemical treatment, that is, the time of the bio-treatment of micro-organisms. Based on the results, it was confirmed that the pre-treatment method using the ultrasonic and the air ejector device of the experiment shows the effect of reducing the water pollutants and odor more effectively in a relatively short time than the conventional advanced oxidation method.

Keywords: Micro-Bubble, Ultrasonic Wave, Complex Odor, Sulfur Compounds, Southeast Asia Wastewater Treatment Market.

JEL Classifications: M3, H8, I11.

* $1^{\text {st }}$ Author. Master's degree completion, Department of Environmental Health \& Safety, Eulji University, Korea. Tel: +82-31-740-7230. E-mail: idrjqnrdl@naver.com

** $2^{\text {nd }}$ Author. Senior Researcher, Department of Environmental Health \& Safety, Eulji University, Korea. Tel: +82-31-740-7230. E-mail: youngdo31@naver.com

*** $3^{\text {rd }}$ Author. Professor, Department of Health Care Management, Catholic Kwandong University, Korea. Tel: +82-33-649-7589. E-mail: leokwon1@cku.ac.kr

**** $4^{\text {th }}$ Author. Professor, Department of Chemical \& Biological Engineering, Gachon University, Korea. Tel: +82-31-750-5594. E-mail: leews@gachon.ac.kr

***** Corresponding Author. Professor, Department of Environmental Health \& Safety, Eulji University, Korea. Tel: +82-31-740-7230. E-mail: awtkw@eulji.ac.kr

\section{Introduction}

The leather industry removes hairs from animals, especially livestock leather, and then treats them with various leather treatments. It is an industry that processes leather as a living material or an industrial material. The leather industry is an industry that processes raw hides and involves a multistep chemical treatment. In this process, a large amount of water and chemicals are introduced. Therefore, the leather industry has a higher level of pollutant discharge such as sewage, odor and waste oil than other industries. It is an environment pollutant discharge industry and a device intensive industry.

As thus, in recent years, leather industry has been recognized as a representative environmental pollution inducing industry due to a large amount of wastewater generated during the leather manufacturing process, solid 
waste, odor and harmful gas. Wastewater is a water pollutant generated in food wastes treatment process(Gal, Kwon, Lee, Choi, Kwon, Seong, \& Kwon, 2018). Therefore, post-treatment of environmental pollutants in addition to environmental preservation technology of technology concept, production technology of concept of pre-treatment technology of environment pollutant is also in a state of urgency, and it is said that clean leather process technology is indispensable industry. In the leather manufacturing process, in the tanning process, which includes the lime process and the demineralization process, which facilitates the smooth tanning process when the oil contained in the raw hides and the salt removal and the hair removal process are performed, the sulfur compound and the nitrogen compound. A large amount of odor inducing substances such as hydrogen sulfide and ammonia are generated, and similar odor inducing substances are generated in the process of treating wastewater used in the process.

Recently, not only in Korea but also in Southeast Asia, the textile industry is in crisis due to the deterioration of export competitiveness along with the deterioration of productivity, rising wages and wastewater. In particular, leather manufacturing industries are treated with various kinds of leather treating agents after removing hairs from animal skin, resulting in a large amount of wastewater and odor gas. Especially, bad smell deteriorates the air quality of the surrounding environment, working conditions, and job satisfaction, thereby deteriorating the productivity of working workers as well as factors of air pollution. Therefore, it is necessary to develop a work process to reduce the odor when processing leather wastewater, and to increase productivity.

The industrial and industrial wastewater treatment markets in Southeast Asia are expected to grow at an annual average growth rate of less than $10 \%$ over the $2015-2020$ period and will grow to more than $\$ 4$ billion by 2020(Takehiko \& Ravi, 2016). Currently, the most urgent projects in the Southeast Asian wastewater treatment industry are small wastewater purification business, water treatment plant, and wastewater treatment business.

On the other hand, the main odor substances generated in the leather maker are composed of ammonia $\left(\mathrm{NH}_{3}\right)$ and hydrogen sulfide $\left(\mathrm{H}_{2} \mathrm{~S}\right)$. Most of the odor reduction technologies use absorption and adsorption methods, but they are inefficient because they need to be combined with other deodorizing technology and have a high maintenance cost. Also, it is necessary to develop the clean process technology of the pre-treatment technology concept because of the organic material which is high in pollutant load and high in decay rate due to the high BOD in the collecting tank which is the cause of the high concentration odor.

Since the wastewater and odor contains high concentration of highly decomposable organic matter and nutrients such as nitrogen and phosphorus, it is not suitable for direct treatment by conventional physicochemical treatment methods or biological methods(Zhou, Selvam, Wong, 2014). Thus, many researchers and research institutes have proposed new treatment methods to address the problem of resolving the problem, but the development of the food waste and odor treatment facility wastewater system is urgently needed to deal with food waste treatment facility wastewater marine emissions in Southeast Asia and Southeast Asia(Kwon, Lee, Kwon, Seong, Kim, \& Kwon, 2017).

Recently, a technique called micro-bubbles(hereinafter referred to as micro-bubbles) has been shown to stably remove odor, especially by nutrient removal and aerobic biological treatment(Jang, Yu, Kang, Kim, Yee, Sung, \& Kim, 2017). Micro-bubbles have been evaluated to increase the dissolved oxygen concentration in the water and generate hydroxyl radicals when destroyed, thereby reducing pollutants in the water tank(Terasaka, Hirabayashi, Nishino, Fujioka, \& Kobayashi, 2011).

Particularly, when ozone is added together with oxygen and air of $50 \mu \mathrm{m}$ or less, buoyancy is small and it takes a long time to stay in the water. It is known that the surface area is large due to micro-bubbles, which is great for wastewater treatment effects(Cha, 2009).

The method of generating minute bubbles can be classified into a pressure-dissolving method by a pump and an ejector-type method as a new method. The pressurizationdissolving method has the disadvantage that it requires a small amount of compressed air and generates high density of micro-bubbles(Maeda, Hosokawa, Baba, Tomiyama, \& Ito, 2015) but requires extra compressed air(Terasaka et al., 2011). Since the ejector uses the venturi principle, it has advantages in terms of economical efficiency and problem of sludge compared to the pressurization-dissolving method, while the size of generated micro-bubbles is relatively large and the distribution of micro-bubble sizes is considerably wide(Sadatomi, 2012). Therefore, this study aims to study cost-effective odor reduction method for micro-bubbles by using ejector and suitable for small-scale work places in Southeast Asia and apply it to the Southeast Asian wastewater market.

\section{Experimental apparatus and method}

\subsection{Research object}

A leather manufacturer located in Ansan-city, Gyunggi-do, South Korea, collected samples from the sink and selected experimental materials. The sample was taken $5 \mathrm{~L}$ at one time and 200L was sampled every 20 minutes for 3 days. The sampling vessel was washed three times with the wastewater sample before filling the sample to maintain the uniformity of the sample, and the collected sample was kept under refrigeration at $4^{\circ} \mathrm{C}$ or less. The properties of the used samples are shown in Table 1. 
Table 1: Characteristics of leather dyeing wastewater

\begin{tabular}{|c|c|}
\hline Items & Value \\
\hline Total nitrogen $(\mathrm{mg} / \mathrm{L})$ & 2,030 \\
\hline Total phosphate $(\mathrm{mg} / \mathrm{L})$ & 79.4 \\
\hline CODcr $(\mathrm{mg} / \mathrm{L})$ & 1,980 \\
\hline Turbidity $(\mathrm{ntu})$ & 36.21 \\
\hline Temperature $\left({ }^{\circ} \mathrm{C}\right)$ & 13.4 \\
\hline $\mathrm{pH}$ & 5.56 \\
\hline $\mathrm{H}_{2} \mathrm{~S}(\mathrm{ppm})$ & 1.5 \\
\hline $\mathrm{NH}_{3}(\mathrm{ppm})$ & 0.6 \\
\hline Complex odor & 3,000 \\
\hline
\end{tabular}

\subsection{Research method}

\subsubsection{Experimental devices and operating conditions}

Experimental setup consisted of circulating water tank-air ejector-ultrasonic device, and circulating wastewater. The air ejector was manufactured with $\varnothing 25 \mathrm{~mm}$ (Inlet) - $\varnothing 30 \mathrm{~mm}$ (Outlet) with reference to Kang's study(2017). The inner diameter of the air intake part was made $10 \mathrm{~mm}$ and circulation motor(2hp). And the odor reduction efficiency was evaluated. The experimental water tank equipped with ultrasonic wave is made of stainless steel with a size of $600 \mathrm{~mm}(\mathrm{~W}) \times 480 \mathrm{~mm}(\mathrm{~L}) \times 1,150 \mathrm{~mm}(\mathrm{H})$, and a transparent acrylic window is installed as shown in Figure 1 below so that the side wall can observe the inside. The ultrasound generator is a $700 \mathrm{~W}$ AC oscillator and a piezoelectric transducer, which is the most widely used device for chemical reaction devices. The circulating motor and the ultrasonic device were set to operate for 12 hours and 12 hours, respectively. The samples of the experimental apparatus were sampled from Sampler Valve and Air Outlet as shown in Figure 1.

(8)

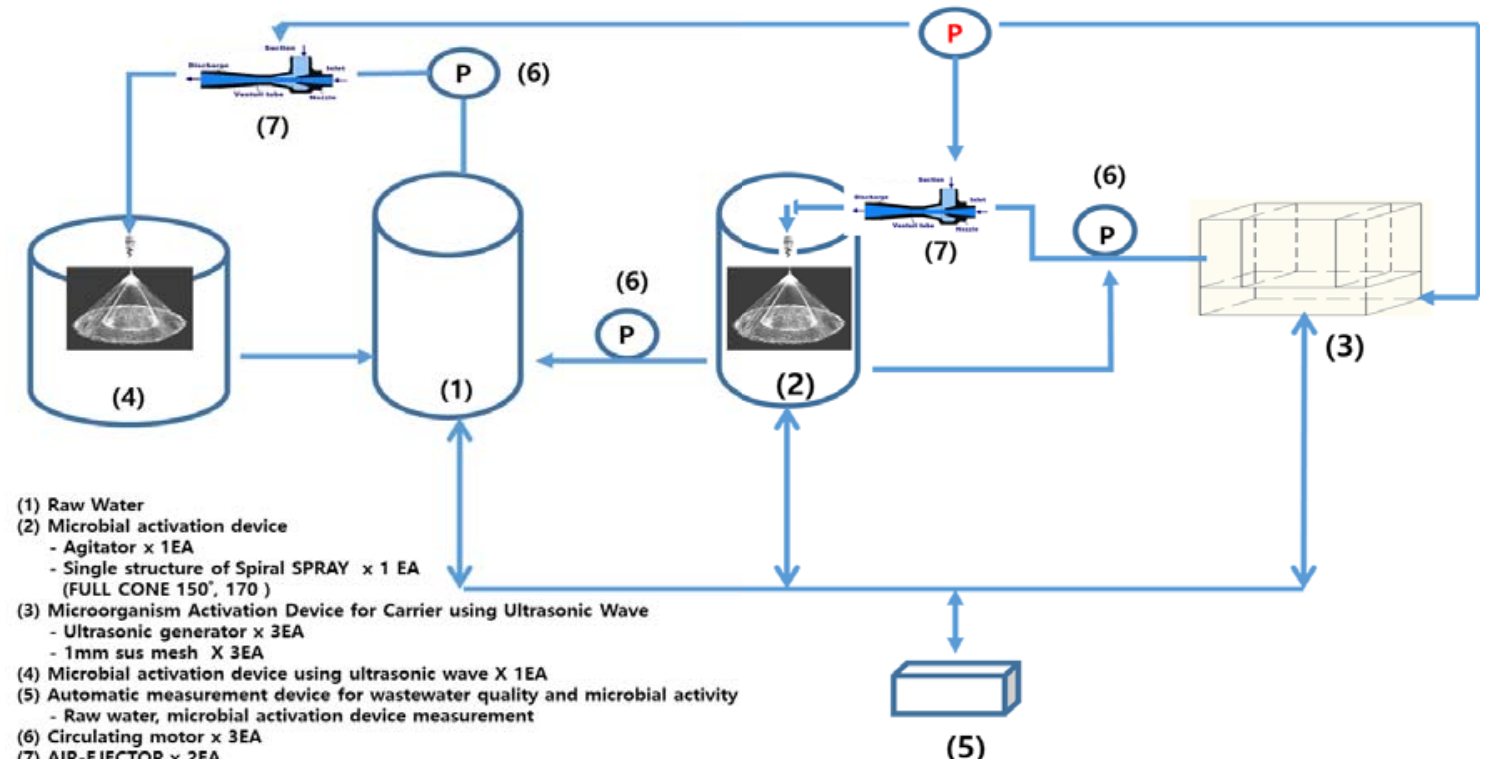

(6) Circulating motor $\times$ 3EA
(7) AIR-EJECTOR $\times 2$ 2EA

(8) Blower $\times$ 1EA

Figure 1: Ultrasonic air ejector pre-treatment system

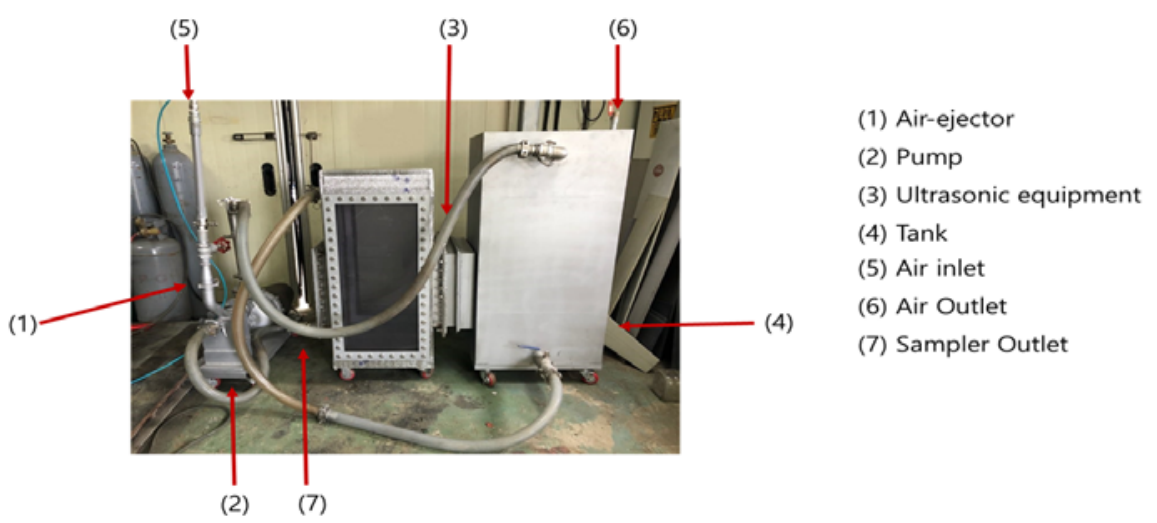

Figure 2: Air ejector-ultrasonic pre-treatment system 
Table 2: Panel information

\begin{tabular}{|c|c|c|c|c|c|c|c|}
\hline \multirow{2}{*}{ Panel } & \multirow{2}{*}{ Gender } & \multirow{2}{*}{ Age } & \multicolumn{4}{|c|}{ Odor intensity recognition test } & \multirow{2}{*}{ Panel compliance } \\
\hline & & & n-Butanol & Acetic acid & Methyl cyclopentenolone & Trimethly-amine & \\
\hline 1 & Man & 29 & $\bigcirc a$ & 4 & 4 & 4 & Suitability \\
\hline 2 & Man & 33 & $\bigcirc$ & 4 & 3 & 4 & Suitability \\
\hline 3 & Woman & 25 & $\bigcirc$ & 4 & 4 & 4 & Suitability \\
\hline 4 & Woman & 22 & $\bigcirc$ & 3 & 3 & 4 & Suitability \\
\hline 5 & Man & 25 & $\bigcirc$ & 4 & 3 & 4 & Suitability \\
\hline 6 & Man & 28 & $\bigcirc$ & 3 & 2 & 4 & Incongruity \\
\hline 7 & Man & 26 & 0 & 2 & 4 & 4 & Incongruity \\
\hline
\end{tabular}

ador recognition

Table 3: Calculation by air dilution sensory method

\begin{tabular}{|c|c|c|c|}
\hline Judge division & Calculation process & Remarks & Total number of dilutions \\
\hline $\mathrm{a}$ & $\mathrm{a}=\sqrt{(3 \times 10)}=5.477$ & Minimum(excluded) & \multirow{3}{*}{$\sqrt[3]{(5.477 \times 30 \times 10)}=11.8$} \\
\hline $\mathrm{b}$ & $\mathrm{b}=100$ & $->$ & \\
\hline $\mathrm{c}$ & $\mathrm{c}=\sqrt{(3 \times 10)}=5.477$ & $->$ & \\
\hline $\mathrm{d}$ & $\mathrm{d}=30$ & $->$ & \\
\hline $\mathrm{e}$ & $\mathrm{e}=10$ & Max(excluded) & \\
\hline
\end{tabular}

※ The calculated dilution factor for a sample that has not been detected in the sample dilution multiplied by the sample dilution factor(for example, 10 is calculated as three times if the answer is incorrect).

\subsubsection{Analysis method}

For the analysis of samples, $\mathrm{COD}_{\mathrm{cr}}, \mathrm{TN}, \mathrm{TP}$, and turbidity were analyzed by the National Environmental Science Institute(2017), and 3M's Microbiological culture was performed using Petri film. $\mathrm{NH} 3$ and $\mathrm{H} 2 \mathrm{~S}$, which are the main odor substances, were carried out using direct-type equipment(SKT100-X5). A sample of the complex odor was set up to collect $5 \mathrm{~L}$ of air at a flow rate of $1 \mathrm{~L} / \mathrm{min}$ using a suction box(Top Trading Co.) and a $5 \mathrm{~L}$ polyester bag(Top Trading Co.). The complex odors were evaluated by selecting five panels as shown in Table 2. Table 3 as below shows the calculation method of the total number of judgement staffs except the maximum and minimum 2 persons among 5 panelists. Statistical analysis of the measured and investigated data was done using $\mathrm{R}$ program.

\subsubsection{Microbial culture method}

Samples are taken from the medium to confirm the first micro-organism and cultured as it is. In Figure $3,1 \mathrm{ml}$ of the sample is diluted 10 times with $9 \mathrm{ml}$ of the easy digestion solution and cultured in the medium. $1 \mathrm{ml}$ of diluted sample is sampled and diluted in $9 \mathrm{ml}$ of dilution solution to make a 10 -fold diluted sample. Using this, it is possible to grasp the number of micro-organisms roughly by diluting to 1010 .

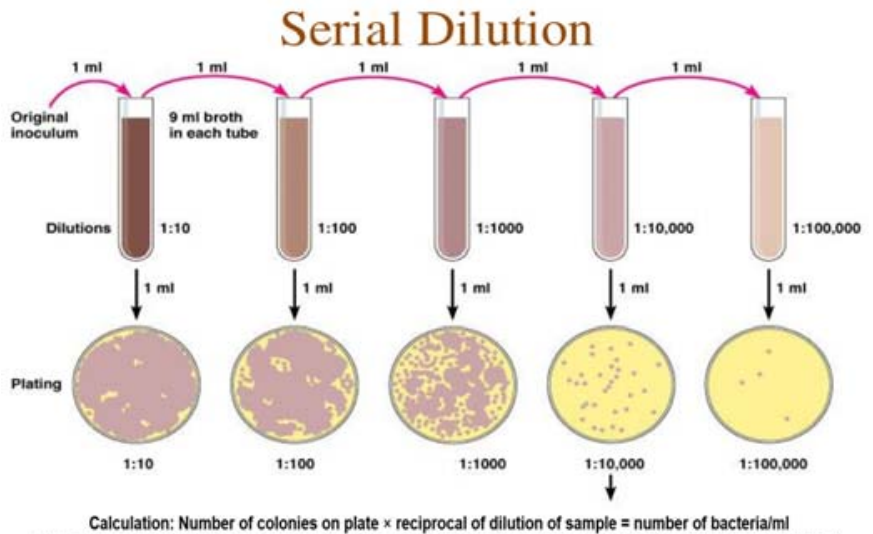

Calculation: Number of colonies on plate $\times$ reciprocal of dilution of sample $=$ number of bacteria/ml (For example, if 32 colonies are on a plate of $11 / 10,000$ dilution, then the count is $32 \times 10,000=320,000 / \mathrm{ml}$ in sample.) Copyright 02004 Pearson Education, Inc., publishing as Benjamin Cummings

Figure 4: To dilute a sample using an easy-dilution

\section{Results and Discussion}

\subsection{Water pollution abatement effect}

Table 4 summarizes the T-N, T-P, COD $\mathrm{cr}$ and turbidity measurements after application of a combined pre-treatment system of air ejector and ultrasonic for 48 hours in total. In terms of $\mathrm{T}-\mathrm{N}>\mathrm{COD}_{\mathrm{cr}}>$ turbidity $>\mathrm{T}-\mathrm{P}$, the efficiency of T-N was $93.25 \%$, while that of T-P was $14.74 \%$. CODcr was $85 \%$ and turbidity was $30.95 \%$. As a result of the oxidation 
of ammonia to $4 \mathrm{NH} 3+3 \mathrm{O}_{2} \rightarrow 2 \mathrm{~N}_{2}+6 \mathrm{H}_{2} \mathrm{O}$, the ammonia nitrogen $\left(\mathrm{NH}_{4}+-\mathrm{N}\right)$ is oxidized and oxidized to nitrate nitrogen $\left(\mathrm{NO}_{3}^{-}\right)$through nitrite nitrogen $\left(\mathrm{NO}_{2}^{-}\right)$. The removal efficiency of TN is excellent. A significant change in the $\mathrm{COD}_{\mathrm{cr}}$ and $\mathrm{T}-\mathrm{N}$ of the sample was observed over the following 24 hours, and a completely changed measurement was obtained after 48 hours. Turbidity also declined somewhat, which is believed to be reduced by breaking into smaller units.

Table 4: Reduction of water pollutants over time after application of experimental equipment

\begin{tabular}{|c|c|c|c|c|c|}
\hline Div. & $\begin{array}{c}\text { Total } \\
\text { nitrogen } \\
(\mathbf{m g} / \mathbf{L})\end{array}$ & $\begin{array}{c}\text { Total } \\
\text { phosphate } \\
(\mathbf{m g} / \mathbf{L})\end{array}$ & $\begin{array}{c}\text { CODcr } \\
(\mathbf{m g} / \mathbf{L})\end{array}$ & $\begin{array}{c}\text { Turbidity } \\
(\mathbf{n t u})\end{array}$ & $\begin{array}{c}\text { Temp. } \\
\left({ }^{\circ} \mathbf{C}\right)\end{array}$ \\
\hline $0 \mathrm{hr}$ & 2,030 & 79.4 & 1,980 & 36.21 & 13.4 \\
\hline $12 \mathrm{hr}$ & 1,820 & 78.1 & 1,200 & 31.19 & 23.8 \\
\hline $24 \mathrm{hr}$ & 928 & 69.6 & 652 & 28.1 & 26.5 \\
\hline $36 \mathrm{hr}$ & 302 & 68 & 334 & 27.08 & 28.8 \\
\hline $48 \mathrm{hr}$ & 137 & 67.7 & 312 & 25 & 25.8 \\
\hline
\end{tabular}

\subsection{Microbial growth state}

After 48 hours of microbial activity, it was confirmed that colonies were detected and activated to such an extent that no more populations were found. In the case of Bacillus bacteria, the cells were cultured in a Petri dish containing agar medium containing nutrients.

Table 5: Reduction of odor substances and increases of microbial activity

\begin{tabular}{|c|c|c|c|}
\hline Time & $\begin{array}{c}\mathbf{p H} \\
([\mathrm{H+}] \mathbf{)}\end{array}$ & $\begin{array}{c}\text { General bacteria } \\
\text { (CFU/ml) }\end{array}$ & $\begin{array}{c}\text { Bacillus sp. } \\
\text { (CFU/ml) }\end{array}$ \\
\hline $0 \mathrm{hr}$ & 5.7 & 0 & 0 \\
\hline $12 \mathrm{hr}$ & 6.1 & $5.1 \times 102$ & $5 \times 10$ \\
\hline $24 \mathrm{hr}$ & 6.2 & $5.1 \times 103$ & $5 \times 103$ \\
\hline $36 \mathrm{hr}$ & 6.6 & $2.3 \times 106$ & $2.3 \times 105$ \\
\hline $48 \mathrm{hr}$ & 7.0 & $2.2 \times 108$ & $6.8 \times 106$ \\
\hline
\end{tabular}

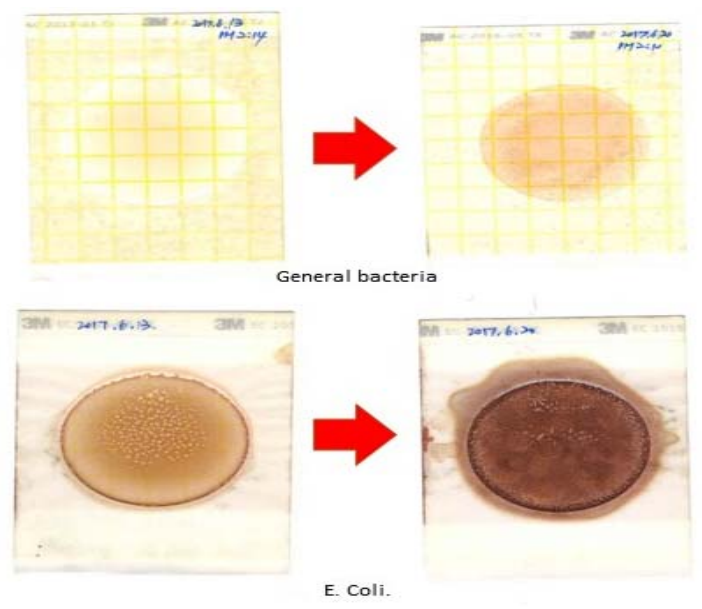

Figure 5: Changes in microbial population before and after application

\subsection{Reduction effect of hydrogen sulfide, ammonia and complex odor}

Hydrogen sulfide $\left(\mathrm{H}_{2} \mathrm{~S}\right)$ and its complex odor exceeded the permissible emission limits and the strict emission limits for initial $\mathrm{H} 2 \mathrm{~S}, \mathrm{NH} 3$, and complex odor concentrations of 1.5 ppm, $0.6 \mathrm{ppm}$ and 3,000 dilution, respectively, while ammonia $\left(\mathrm{NH}_{3}\right)$ was within the emission limit. In Tsuge's study(2010), it can be interpreted that during the process of micro-bubbles, the pressure inside the bubbles is increased and the ions accumulated on the surface generate hydroxyl radicals to remove the main odor substances due to the chemical chain reaction. As time went on, the concentration of hydrogen sulphide was reduced by up to $80 \%$, and ammonia was considered to be reduced by $50 \%$. Especially, in the case of compound odor, it was the first 3,000 dilution, but it took 36 hours until reaching the limit value of 1,000 in the industrial area, and 60 hours until reaching the strict emission standard in other areas.

Table 6: Odor reduction and microbial differences over time after application of experimental equipment

\begin{tabular}{|c|c|c|c|}
\hline Div. & $\mathbf{H}_{2} \mathbf{S}$ (ppm) & $\mathbf{N H}_{3}$ (ppm) & $\begin{array}{c}\text { Complex odor } \\
\text { (OU/Unit) }\end{array}$ \\
\hline $0 \mathrm{hr}$ & 1.5 & 0.6 & 3,000 \\
\hline $12 \mathrm{hr}$ & 1.5 & 0.6 & 2,080 \\
\hline $24 \mathrm{hr}$ & 1.3 & 0.5 & 1,442 \\
\hline $36 \mathrm{hr}$ & 1.3 & 0.4 & 1,000 \\
\hline $48 \mathrm{hr}$ & 0.7 & 0.4 & 669 \\
\hline $60 \mathrm{hr}$ & 0.4 & 0.3 & 300 \\
\hline $72 \mathrm{hr}$ & 0.3 & 0.2 & 300 \\
\hline $84 \mathrm{hr}$ & 0.3 & 0.1 & 300 \\
\hline $96 \mathrm{hr}$ & 0.1 & 0.1 & 120 \\
\hline $108 \mathrm{hr}$ & 0.1 & 0.1 & 120 \\
\hline
\end{tabular}

${ }^{*}$ Odor and water pollution was worse than other processes due to the decay of raw hide.

\section{Conclusion}

This study was conducted to select dyeing wastewater from a fur factory located in Ansan-city, Gyunggi-do, South Korea. Leather wastewater generates a large amount of refractory wastewater and is classified as a representative pollution industry due to the generation of odor. In the process of generating odor, deodorization tank, collecting tank and concentration tank are generating high concentration odor, and countermeasures are needed. In the case of the collecting tank, it was found that the condition of high concentration of

The wastewater from a leather factory, which is a highly concentrated non-degradable wastewater, was selected as an experimental sample to confirm the effect of reducing the 
The wastewater from a leather factory, which is a highly concentrated non-degradable wastewater, was selected as an experimental sample to confirm the effect of reducing the amount of complex odor and specified odor substances by micro-bubbles. The results of this study were as follows.

1) The efficiency of water quality improvement was in the order of T-N > CODcr > turbidity > T-P. Especially, T-N showed high efficiency of $93.25 \%$ while T-P showed low efficiency of $14.74 \%$. CODcr was $85 \%$ and turbidity was $30.95 \%$.

2) As a result, microbial culture increased with time from $0 \mathrm{CFU} / \mathrm{ml}$ at the initial stage, and the population increased and $\mathrm{pH}$ changed from 5.7 to $\mathrm{pH} 6.1$ at 12 hours. After 48 hours, it was confirmed that the population was increased by countless times. Also, the $\mathrm{pH}$ was ascertained to be 7.0.

3) The complex odor was sampled at intervals of 12 hours and measured by air dilution sensory method, and it was confirmed that it decreased from maximum 3,000 to at least 120 times. It took 36 hours to reach industrial zone emission limits and it took 60 hours to reach stringent emission limits in other areas.

4) As a result of selecting ammonia and hydrogen sulfide, ammonia was reduced from $0.6 \mathrm{ppm}$ to $0.1 \mathrm{ppm}$. Hydrogen sulfide was reduced from $1.5 \mathrm{ppm}$ to $0.1 \mathrm{ppm}$, hydrogen sulfide decreased by up to $80 \%$, and ammonia decreased by $50 \%$. It was confirmed that pre-treatment with ultrasonic wave and air ejector improves aerobic digestion performance. The micro-bubbles generated by the air ejector are considered to decompose organic substances by forming hydroxyl radicals. It can be expected to have an economical odor removal rate which can shorten a considerable time in the subsequent microbial treatment.

Southeast Asia has a weak infrastructure for the environment industry and is similar to the environment conditions of the 1960s and 1980s in the past. Technology demand for medium and small-scale environmental industries and environment basic facilities is greatly expanding.

Currently, Southeast Asia hopes that Korea's environment industry, such as energy-reduction facilities, waste disposal and final disposal business, can make a matchmaking with Southeast Asia. Therefore, cost-effective wastewater and odor reduction using micro-bubbles and ultrasound will be very helpful for the Southeast Asian wastewater market.

\section{References}

Cha, H. S. (2009). Present State and Future Prospect for Microbubble Technology. Bulletin of food technology, 22(3), 544-552.
Gal, W. M., Kwon, K. T., Lee, W. S., Choi, E. M., Kwon, L. S., Seong, S. H., \& Kwon, W. T. (2018). A Study on Improvement of Distribution Facility in Wholesale Agricultural Products Market. Journal of Distribution Science, 16(2), 53-65.

Handforth, S. L., \& Tilley, J. N. (1934). Catalysts for Oxidation of Ammonia to Oxides of Nitrogen. Industrial \& Engineering Chemistry, 26(12), 1287-1292. https://doi.org/10.1021/ie50300a016

Jang, J. K., Yu, J. J., Kang, S. W., Kim, T. Y., Yee P., Sung, J. H., \& Kim, Y. H. (2017). Simultaneous Removal of Organic Pollutants, Nitrogen, and Phosphorus from Livestock Wastewater by MicrobubbleOxygen in a Single Reactor. Journal of Korean Society of Environmental Engineers, 39, 599-606.

DOI: 10.4491/KSEE.2017.39.11.599

Kang, S. H., \& Park, Y. C. (2017). Study on the Swirling Motion Effect of Ejector Performance. Journal of the Korea Academia-Industrial cooperation Society, 18(4), 544-549.

Kim. H. J., Bae. Y. S., Oh. C. H., Kim. T. H., Kim. J. B., Ryu. H. R., \& Kim. T. H. (2009). A Study on Management Improvement of Deodorization Equipment of Food Waste Treatment Facility. Korean Journal of Odor Research and Engineering, 8(1), 20-30.

Kang, H., Lee S. H., Lee W. S., Kwon J. H., \& Jung, K. J. (2012). Study on phosphorus removal in the secondary effluent by flotation using micro-bubble liquid film system. J. Korea Soc. Environ. Eng, 34(1), 42-48.

Kwon, W. T., Lee, J. C., Kang, H. S., Kwon, L. S., Kim, H. G., \& Gal, W. M. (2015). Odorant removing effect of a multi process -The combination of scrubber, UV, adsorption-. Journal of odor and indoor environment, 14(2), 85-92.

Kwon, K. T., Lee, W. S., Kwon, L. S., Seong, S. H., Kim, Y. D., \& Kwon, W. T. (2017). Entry into the Southeast Asian Energy Market from the Sales Promotion Viewpoint. Journal of Distribution Science, 15(10), 29-39.

Kwon, W. T., Lee, J. C., Kang, H. S., Kwon, L. S., Kim, H. G., \& Gal, W. M. (2015). Odorant removing effect of a multi process -The combination of scrubber, UV, adsorption-. Journal of odor and indoor environment, 14(2), 85-92.

Lee, J. C., Kwon, L. S., Lee, W. Sic., \& Kwon, W. T.(2016). A study on odor removal efficiency of wastewater treatment plant by multiple process, Journal of odor and indoor environment, 15(4), 385-391.

Maeda, Y., Hosokawa, S., Baba, Y., Tomiyama, A., \& Ito, Y. (2015). Generation mechanism of micro-bubbles in a pressurized dissolution method. Experimental Thermal and Fluid Science. 60. 10.1016/j.expthermflusci.2014.09.010.

Michio, S., Akimaro, K., Hidetoshi, M., \& Shinji, S.(2012). Micro-bubble generation rate and bubble dissolution rate into water by a simple multi-fluid mixer with orifice 
and porous tube. Experimental Thermal and Fluid Science, $41, \quad 23-30 . \quad$ ISSN 0894-1777, https://doi.org/10.1016/j.expthermflusci.2012.03.002.

Ministry of Environment(ME) (2007). '06 Analysis of complaints against odor \& '07 Management direction for odor(pp.5-6).

National Environmental Science Institute. (2017). Water pollution process test standard, ES 04362.1c Total ultraviolet, visible line spectroscopy. Ministry of Environment, 1-7.

National Environmental Science Institute. (2017). Water pollution process test standard, ES 04315.3c COD, Titration method, Potassium dichromate method. Ministry of Environment, 1-7.

National Environmental Science Institute. (2017). Water pollution process test standard, ES $04363.1 \mathrm{~b}$ Total nitrogen-ultraviolet, visible-line spectroscopy-oxidation. Ministry of Environment, 1-6.

Sadatomi, M., Kawahara, A., Matsuura, H., Shikatani, S. (2012). Micro-bubble generation rate and bubble dissolution rate into water by a simple multi-fluid mixer with orifice and porous tube, Experimental Thermal and Fluid Science, 41, 23-30.

Tsuge, S. (2010). The latest technology on microbubbles and nanobubbles ㅍ. CMC publishing, 140-167.

Takehiko, N., \& Ravi, N. (2016). Asian Water Development Outlook 2016 Strengthening Water Security In Asia and The Pacific. Asian Development Bank. ISBN 978-92-9257-543-4

Terasaka, K., Hirabayashi, A., Nishino, T., Fujioka, S., \& Kobayashi, D. (2011). Development of microbubble aerator for waste water treatment using aerobic activated sludge, Chemical Engineering Science, 66, 3172-3179.

Tsuge, S. (2010). The latest technology on microbubbles and nanobubbles. CMC publishing, 140-167.

Zhou, Y., Selvam, A., \& Wong, J. (2014). Evaluation of humic substances during co-composting of food waste, sawdust and Chinese medicinal herbal residues. Bioresource Technology, 168, 229-234. 